\title{
Influence of the tool's feed on the thickness of burrs at the pipe end during stack cutting with a circular saw
}

\author{
Olga A. Makarova, Alexey A. Zhdanov, Alla A. Kozhevnikova, Ruslan I. Arzhukhanov*, \\ and $V u$ Van Giang \\ Volgograd State Technical University, 400005, Volgograd, Lenin avenue, 28, Russia
}

\begin{abstract}
By means of mathematical modeling of the distribution of the temperature field in the workpiece during stack cutting of cold rolled metal, the results of heat distribution in the pipe material were obtained at various feeds $S$. The temperature field of the pipe material at feeds $0.008 \mathrm{~m}$ / s $(0.0012 \mathrm{~mm} /$ tooth $)-0.028 \mathrm{~m} / \mathrm{s}(0.0042 \mathrm{~mm} /$ tooth $)$ is studied when cutting a stack of blanks from workpieces with a diameter of $42 \mathrm{~mm}$.
\end{abstract}

Modern manufacturing commonly uses the process of high-speed cutting of cold rolled products with circular saws. One of the main problems in ensuring the quality of the cut is the appearance of a burr at the end of the pipe. Since the feed per tooth is by 2-3 orders less than the radius of curvature of the cutting edge, the process of high-speed cutting is considered as thermofrictional. The separation of rolled products is accompanied by intense heating of the surface layers and their squeezing out of the deformation zone. Since during processing at high speeds $(100 \mathrm{~m} / \mathrm{s})$ the workpiece heats up quite strongly, this affects the physical and mechanical properties of the pipes, thus affecting the strength of the material in the burr formation zone. Hence, it becomes necessary to study the effect of temperature fields in the burr formation zone, depending on the feed.

\section{The main parameters of thermal friction cutting with a sliding- frame saw}

The process of high-speed cutting of cold rolled steel was investigated on a unit for stack cutting with a sliding-frame saw of VTZ, AO $[1,2]$. The main geometric characteristics of the saw used for stack cutting for cold rolled metal are given in Table 1.

\footnotetext{
* Corresponding author: kinnomans@mail.ru
} 
Table 1. Basic geometric characteristics of the saw and the cutting process

\begin{tabular}{|c|c|}
\hline Diameter of the cutting disc, $\mathrm{mm}$ & 2000 \\
\hline Tooth height, $\mathrm{mm}$ & 10.3 \\
\hline Thickness of the cutting disc, $\mathrm{mm}$ & 8 \\
\hline Number of teeth & 400 \\
\hline Cutting speed, $\mathrm{m} / \mathrm{s}$ & 105 \\
\hline Feed, $\mathrm{m} / \mathrm{s}$ & $0.008-0.028$ \\
\hline
\end{tabular}

The cutting process is the friction of the saw blade surface with the workpiece (pipe stack), which leads to an increase in temperature in the contact zone and squeezing out of the heated metal from the deformation zone. Heating of the metal in the cutting zone is one of the reasons for the formation of burrs. Therefore, an important task is to study the size of the propagation of temperature fields.

\section{Investigation of the effect of temperature fields on burr formation}

Burrs at the ends of pipes during cutting arise due to the plastic flow of the metal under the action of cutting forces and high temperatures.

When cutting a stack of workpieces, a large amount of heat is generated from friction, which leads to heating of a significant volume of the processed material in the near-contact zone. When the saw approaches the pipe edge at the end of the cut, this heated volume of material first deforms and then breaks to form a burr at the pipe end.

To determine the onset of deformation and burr detachment, it is necessary to describe the temperature field arising from the heating of the contact zone by the saw.

To solve the problem of the size of the temperature field, the method of heat sources is used. The contact zone directly under the saw can be represented as a body, which is exposed to a strip-like heat source moving at a speed S.

The material temperature at a distance $y$ from the contact zone can be calculated with formula (1) $[3,4]$ :

$$
T_{\text {pipe }}(y)=1550 \cdot \exp \left(-\frac{S \cdot y}{2 \omega_{m p}}\right),
$$

where $S$ - saw feed speed per second, $\mathrm{m} / \mathrm{s}$;

$\omega_{\text {pipe }}-$ coefficient of thermal diffusivity of the pipe material, $\mathrm{m} 2 / \mathrm{s}$.

When the saw approaches the edge of the pipe at the end of the cut, the heat flow is reflected from the interface, which increases the temperature of the material. Applying the method of reflected heat sources, the temperature at the boundary (at a distance $y$ from the heat source) is calculated with formula (2):

$$
T_{\text {pipe }}(y)=1550 \cdot \exp \left(-\frac{S \cdot y}{2 \omega_{\text {pipe }}}\right)+1550 \cdot \exp \left(-\frac{S \cdot(2 h-y)}{2 \omega_{\text {pipe }}}\right),
$$

where $h$-distance from the saw to the outer wall of the pipe.

Since heat from the contact zone spreads not only to the area under the saw, but also along the edges of it, to describe the distribution of heat in the pipe material along the edges from the saw to the rod, two half-planes are added that are heated from a linear heat source. 
Thermal field for a linear heat source moving with speed $S$ on the surface of the half-space is calculated with formula (3):

$$
T_{\text {pipe }}(y, z)=1550 \cdot \exp \left(-\frac{S \cdot y}{4 \omega_{\text {pipe }}}\right) \cdot K_{0}\left[\frac{S \cdot \sqrt{y^{2}+(z+0,001)^{2}}}{4 \omega_{\text {pipe }}}\right]
$$

The outer and inner surfaces of the pipe are also boundaries and change the temperature field in the material along the edges of the saw. For a half-space, the temperature at a point with coordinates $(y, z)$ is equal to the sum of temperatures from the actual and reflected sources:

$$
\begin{aligned}
& T_{\text {pipe }}(y, z)=T_{p t} \cdot \exp \left(-\frac{S_{M} \cdot y}{4 \omega_{\text {pipe }}}\right) \cdot K_{0}\left[\frac{S_{M} \cdot \sqrt{y^{2}+(z+0.001)^{2}}}{4 \omega_{\text {pipe }}}\right]+ \\
& +T_{p t} \cdot \exp \left(-\frac{S_{M} \cdot(2 h-y)}{4 \omega_{\text {pipe }}}\right) \cdot K_{0}\left[\frac{S_{M} \cdot \sqrt{(2 h-y)^{2}+(z+0.001)^{2}}}{4 \omega_{\text {pipe }}}\right]+ \\
& +T_{\text {pipe }} \cdot \exp \left(-\frac{S_{M} \cdot\left(2\left(h-h_{p t}\right)-y\right)}{4 \omega_{\text {pipe }}}\right) \cdot K_{0}\left[\frac{S_{M} \cdot \sqrt{\left(2\left(h-h_{p t}\right)-y\right)^{2}+(z+0.001)^{2}}}{4 \omega_{\text {pipe }}}\right],
\end{aligned}
$$

where $h_{c m}$ - pipe wall thickness.

The moments of formation and rupture of the burr will be determined by the achievement of the ultimate strength and yield strength in the material, which depend on the temperature in the processing zone. As soon as the stresses in the material become equal to the yield point, burr formation begins. Deformation of the burr occurs with a decrease in its thickness to the limiting value, which leads to the detachment of the burr when the ultimate strength is reached.

The speed of movement of heat sources affects the propagation of the temperature field. Calculation of temperature fields for different values of the tool feed $(0.008-0.0028 \mathrm{~m} / \mathrm{s})$ allows one to determine the thickness of the burr.

Figure 1 shows the distribution of the temperature field when feeding $\mathrm{S}=0.008 \mathrm{~m} / \mathrm{s}$.

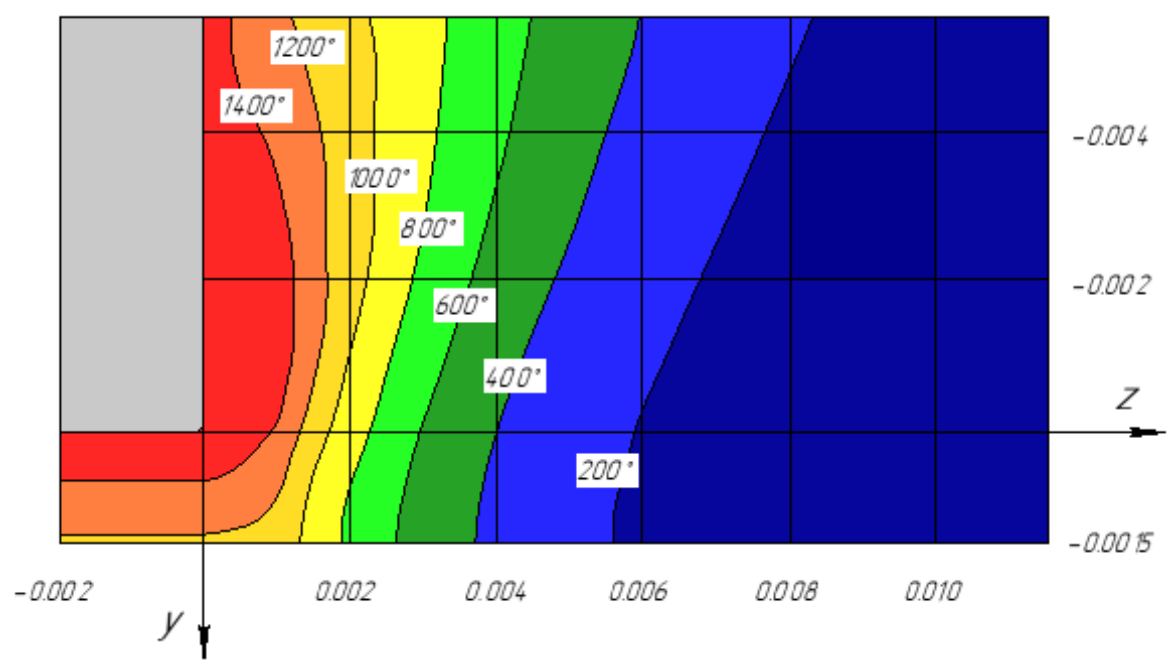

Fig. 1. Temperature field of the pipe material when feeding $S=0.008 \mathrm{~m} / \mathrm{s}$ 
The low tool feed rate provides significant heating of the workpiece material in the cutting zone.

Figure 2 shows the distribution of the temperature field when feeding $S=0.016 \mathrm{~m} / \mathrm{s}$

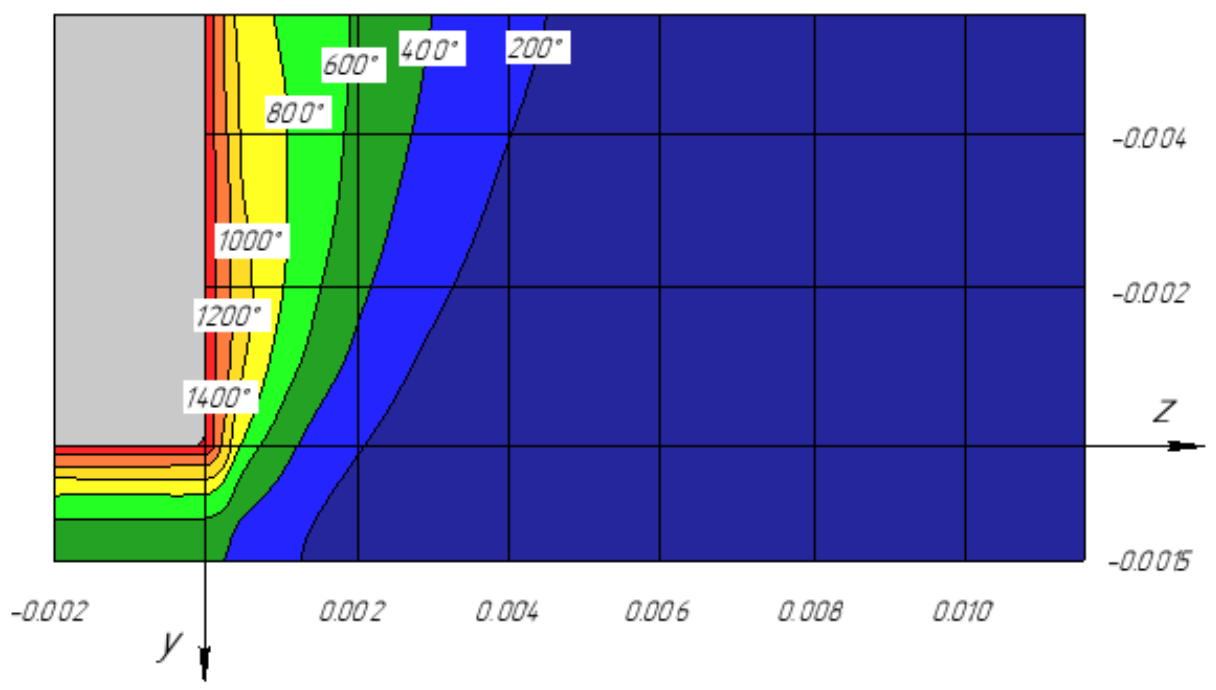

Fig. 2. Temperature field of the pipe material when feeding $S=0.016 \mathrm{~m} / \mathrm{s}$

At given tool feed rates, a decrease in the propagation of the temperature field is observed.

Figure 3 shows the distribution of the temperature field when feeding $\mathrm{S}=0.028 \mathrm{~m} / \mathrm{s}$

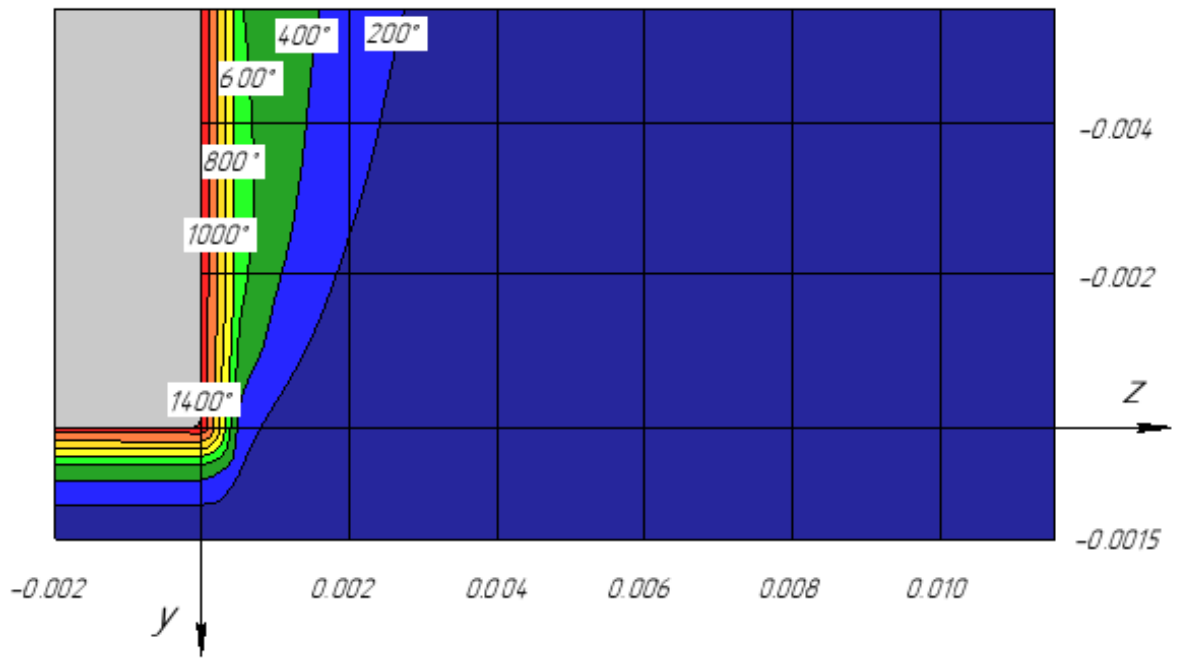

Fig. 3. Temperature field of the pipe material when feeding $\mathrm{Sm}=0.028 \mathrm{~m} / \mathrm{s}$

While providing high feed rates of the tool, the thermal field is small.

Based on the obtained result of modeling the distribution of the temperature field at different feeds, we can conclude that, with an increase in feed, the intensity of heating of the pipe material decreases, consequently the volume of material required for the formation of a burr decreases. 


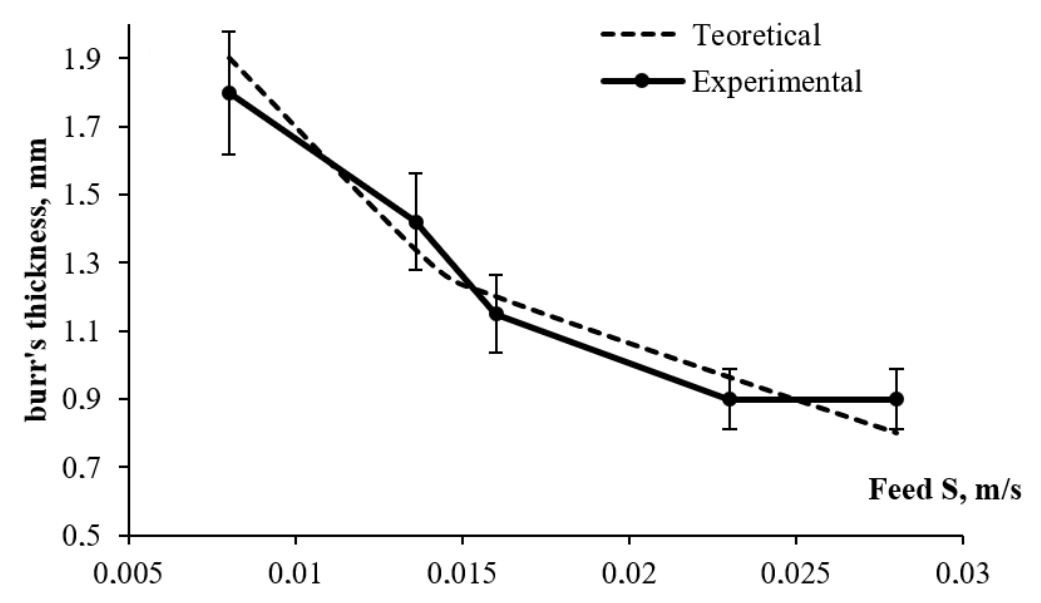

Fig. 4 - Graph of the dependence of the burr thickness in mm on the feed value in $\mathrm{m} / \mathrm{s}$

An experimental study (Figure 4) showed the dependence of the burr thickness on the saw feed. With an increase in feed, the distribution of the temperature field decreases, as a result, a decrease in the burr thickness occurs.

\section{References}

1. A.I. Bannikov, A.A. Bannikov, A.I. Kurchenko, N.A. Dyatlov, I.L. Permyakov, Increasing the efficiency of thermo-friction cutting of rolled pipes (Povyshenie effektivnosti termofriktsionnoj rezki truboprokata), STIN, 10, pp. 34-37 (2010)

2. Yu.N. Polyanchikov, A.I. Bannikov, A.I. Kurcheniko, O.A. Makarova, Investigation of the size of the burr during thermal friction cutting (Issledovanie razmerov zausentsa pri termofriktsionnom rezanii), Izvestiya VolgGTU, Progressive technologies in mechanical engineering (Progressivnye tekhnologii v mashinostroenii), 4(9), pp. 33-35 (2008)

3. A.N. Reznikov, Thermal physics of materials machining processes (Teplofizika protsessov mekhanicheskoy obrabotki materialov), M.: Mashinostroyeniye, Theory of welding processes (Teoriya svarochnyh processov), M.: Izd-vo MGTU i. NE Baumana, p. 279 (1981)

4. A.V. Konovalov et al., Theory of welding processes (Teoriya svarochnyh processov), M.: Izd-vo MGTU i. NE Baumana, p. 279 (2007). 